\title{
Non Incretin Effects of DPP-4 Inhibitors: Comparative Study
}

\author{
A.S.A.Bhatti ${ }^{1}$, Aliya Shabbir ${ }^{2}$, Abdul Waheed Shehzad ${ }^{3}$, M.A.Bhatti ${ }^{4}$ \\ Department of Pharmacology, Shalamar Medical and Dental College Lahore ${ }^{1,2}$. The Children Hospital and Institute of Child Health, Lahore ${ }^{3}$. \\ Department of Pharmacology, Avicenna Medical College, Lahore ${ }^{4}$.
}

\begin{abstract}
Background: Diabetes mellitus is a metabolic syndrome that adversely affects all parts of the body especially cardiovascular system. Dipeptidyl peptidase-4 (DPP-4) is a multifunctional protein and its inhibition has diverse effects. DPP-4 inhibition was shown to improve survival rate after myocardial infarction in mice. Beneficial myocardial metabolic effects of DPP-4 inhibitors have been observed in experimental models. Cardiovascular outcome trials of DPP-4 inhibitors show variable adverse cardiovascular events.

Objective: This experimental study was aimed to study the direct cardiovascular effects of DPP-4 Inhibitors on chronotropicity (Heart Rate,HR), inotropicity (Apical Force and; dP/dt(max), ECG and Coronary Flow(C.F) and detect its potential useful and harmful effects on cardiovascular parameters.

Methods: The effects of graded doses $\left(10^{-9}-10^{-6} \mathrm{M}\right)$ of Sitagliptin (S) and Vildagliptin(V) were observed on retrograde perfused isolated rabbit hearts with warm Krebs-Henseliet solution on Radnoti working heart system. Fifty four(54) rabbits were grouped into nine groups i.e ; I(S1), II(S2), III(S3), IV(S4), V(S5), VI(S6), VII(V1), and VIII(V2) and IX(V3) each comprising of six animals(n=6).Effects of experimental drugs were observed on chronotropicity(HR), inotropicity (Apical Force and Peak rate of rise of LVP i.e; $\mathrm{dP} / \mathrm{dt}(\max$ ) and Coronary flow(CF). The results were statistically analyzed with Graph Pad Grism and wherever necessary paired or unpaired "t" test was applied.

Conclusion: Sitagliptin and Vildagliptin both have suppressant effects on HR. Sitagliptin has positive and Vildagliptin had negative inotropic effects. Both drugs $\left(10^{-8}-10^{-6} \mathrm{M}\right)$; decrease coronary flow but have no significant effect on ECG.
\end{abstract}

Key Words: T2DM, IHD, DPP-4 Inhibitors, Apical force, $\mathrm{dP} / \mathrm{dt}(\max )$.

\section{INTRODUCTION}

Diabetes mellitus can result into Coronary Heart Disease (CHD) later on leading to an acute myocardial infarction ${ }^{1,2,3}$. Gliptins have cardiovascular depressant effects as a result of inhibitory action on the dipeptidyl peptidase-4 enzyme $^{4,5}$. It has been observed that Sitagliptin reduces elevated cardiac fatty acid uptake and oxidation, prevents myocardial fibrosis and reduces oxidative stress in cardiomyocytes in small animals ${ }^{6}$. The role of DPP-4 inhibitors on the heart is still unclear ${ }^{7}$. In addition to the insulinotropic effect, GLP-1 signaling has been reported to modulate cardiac functions. In animals DPP-4 inhibition has shown to improve survival rate after myocardial infarction but the precise mechanism is not known. There is also need of comparative study of direct cardiovascular effects of DPP-4 Inhibitors.

\section{MATERIALS AND METHODS}

This experimental study was carried out in the laboratory of the Pharmacology Department, Shalamar Medical and Dental College Lahore after the approval of the project from Institutional Review and Ethical Board (IRB) of Shalamar Medical and Dental College, Lahore and according to the Guide for the Care and Use of Laboratory Animals published by the US National Institutes of Health (National Institutes Of Health Publication 85-23, revised 1996).

Grouping of Animals: Fifty four (54) rabbits were grouped into seven groups i.e; I(S1), II(S2), III(S3), IV (S4), V (S5), VI (S6), VII (V1), VIII (V2) and IX(V3) each comprising of six animals $(n=6)$

Note: Groups 1, 11, 111, V1, V, V1 were treated with four concentrations or doses i. $10^{-9} \mathrm{M}, 10^{-8} \mathrm{M}$, $10^{-7} \mathrm{M}, 10^{-6} \mathrm{M}$ while Groups V11, V111 and 1 Xwere treated with $10^{-8} \mathrm{M}, 10^{-7} \mathrm{M}$, and $10^{-6} \mathrm{M}$. 
Preparation of Heart for Perfusion: 54 normal male rabbits (weighing between $1.5-2 \mathrm{~kg}$ ) were purchased from the local market. Each rabbit was injected 5000IU (1ML) of heparin through the marginal ear vein one hour before slaughtering. Heart was removed from the chest after midsternal incision and immediately placed in an ice cold Krebs-Henseleit solution The heart was mounted on Langendorff working heart system via aortawhose stump was secured about $3 \mathrm{~mm}$ on the grooved perfusion cannula by a silk ligature. A weight was attached to the heart apex and left to hang freely exerting resting tension of one gram. Heart was perfused in retrograde at a constant flow of $52 \mathrm{ml} / \mathrm{min}$ with warm Krebs-Henseleit solution. It was allowed to stabilize for $30 \mathrm{mins}$ in the perfusate which was equilibrated with $95 \% \mathrm{O} 2$ and $5 \% \mathrm{CO} 2$ with Krebs-Henseleit solution with $\mathrm{pH}$ of 7.35 at $37^{\circ} \mathrm{C}$. A saline-filled balloon catheter was inserted into the left ventricle which was often used to measure isovolumetric work. Balloons slightly larger than the maximum expanded volume of the ventricle were used to avoid effects of measuring the resistance of the balloon to stretch.

Drugs Used: Oral hypoglycemic was procured from the Wilshire pharmaceutical industry in the powder form free from any base. Following drugs were employed: Sitagliptin(S) and Vildagliptin(V)

\section{RESULTS}

1. Sitagliptin (10-9 - 10-7M) and Vildagliptin (10-8 - 10-4M) have suppressant effects on HR (Fig.1).

2. Sitagliptin (10-9 - 10-4M) has positive and Vildagliptin (10-8 - 10-4M) negative inotropic effects (Fig.2, 3).

3 . Both drugs $(10-8-10-6 \mathrm{M})$ decrease coronary flow (Fig.4). However, Sitagliptin (10-4M) is increases coronary flow.

4. There was no significant effect on ECG ( $R$ and ST-segments) of individual drugs (Table 1).

5. There was significant difference in R and STsegments when the results of two drugs were compared.

It means with decreased heart rate, coronary flow was also decreased with administration of both drugs. It seems that both drugs have direct suppressants effects on conducting tissue and myocardium and cause decreased coronary flow. This effect is also demonstrated by Vildagliptin in the form of significant decreased contractility of myocardium. Sitagliptin has positive inotropicity (Table 1).The results were statistically analyzed with graph Pad prism and wherever necessary paired or unpaired " $\mathrm{t}$ " test was applied.

Effects of Drugs on Heart Rate, Apical Force, Max dp/dt, Coronary Blood Flow

Fig. 1

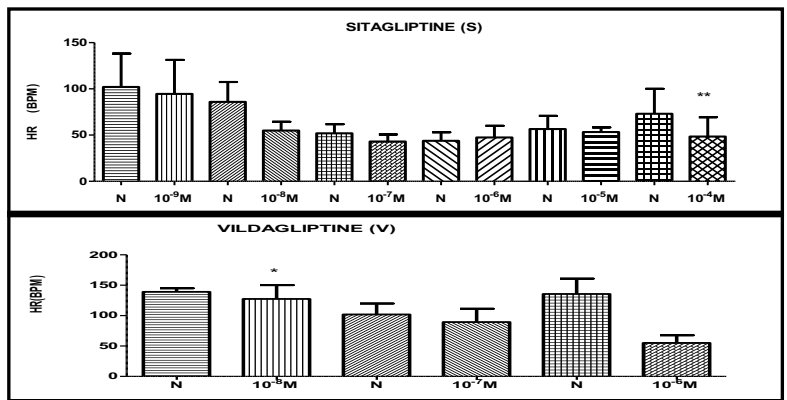

Fig: 2

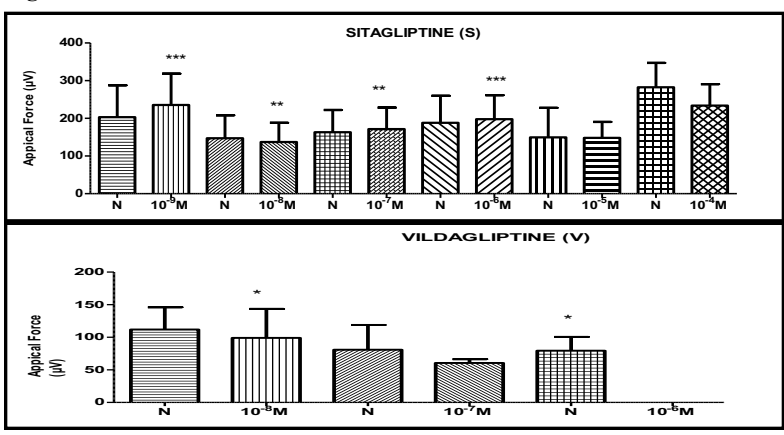

Fig: 3

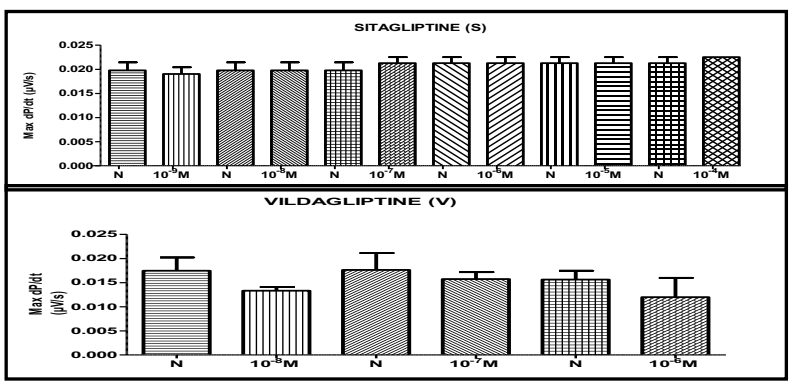

Fig: 4

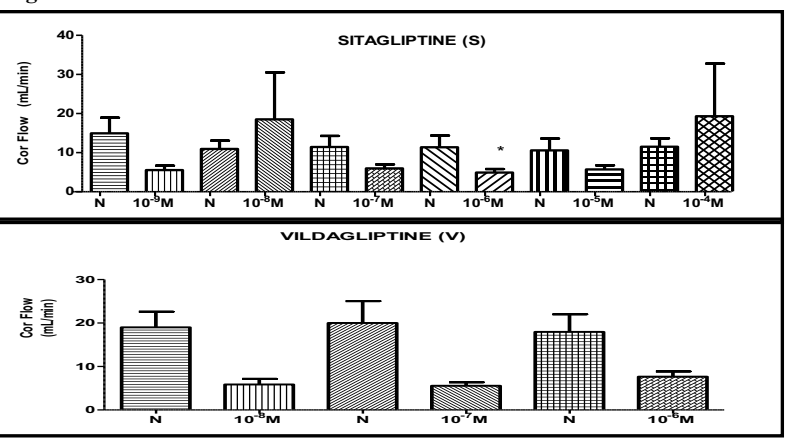


Table No: 1

\begin{tabular}{|c|c|c|c|}
\hline \multicolumn{4}{|c|}{ Comparative Study of Effects of Sitagliptin (S) and Vildagliptin (V) } \\
\hline Drugs & & Mean \pm SE & "p" Value \\
\hline \multicolumn{4}{|c|}{ Heart Rate (BPM) } \\
\hline SITAGLIPTIN & $\mathrm{S}\left(10^{-8} \mathrm{M}\right)$ & $111.5 \pm 6.611$ & \multirow{2}{*}{$\mathrm{p}>0.05$} \\
\hline VILDA GLIPTIN & $\mathrm{V}\left(10^{-8} \mathrm{M}\right)$ & $113.8 \pm 22.84$ & \\
\hline SITAGLIPTIN & $\mathrm{S}\left(10^{-7} \mathrm{M}\right)$ & $111.2 \pm 6.680$ & \multirow{2}{*}{$\mathrm{p}>0.05$} \\
\hline VILDA GLIPTIN & $\mathrm{V}\left(10^{-7} \mathrm{M}\right)$ & $92.90 \pm 24.77 \mathrm{~N}=5$ & \\
\hline \multicolumn{4}{|c|}{ Apical Force $(\mu \mathrm{V})$} \\
\hline SITAGLIPTIN & $\mathrm{S}\left(10^{-8} \mathrm{M}\right)$ & $137.3 \pm 50.94$ & \multirow{2}{*}{$\mathrm{p}>0.05$} \\
\hline VILDA GLIPTIN & $\mathrm{V}\left(10^{-8} \mathrm{M}\right)$ & $99.00 \pm 44.58$ & \\
\hline SITAGLIPTIN & $\mathrm{S}\left(10^{-7} \mathrm{M}\right)$ & $171.6 \pm 56.88$ & \multirow{2}{*}{$\mathrm{p}>0.05$} \\
\hline VILDA GLIPTIN & $\mathrm{V}\left(10^{-7} \mathrm{M}\right)$ & $60.60 \pm 5.793$ & \\
\hline \multicolumn{4}{|c|}{ Max dP/dt $(\mu V / s)$} \\
\hline SITAGLIPTIN & $\mathrm{S}\left(10^{-8} \mathrm{M}\right)$ & $0.019 \pm 0.0016$ & \multirow{2}{*}{$\mathrm{p}<0.05^{* *}$} \\
\hline VILDA GLIPTIN & $\mathrm{V}\left(10^{-8} \mathrm{M}\right)$ & $0.012 \pm 0.0006$ & \\
\hline \multicolumn{4}{|c|}{ "R" Wave Amplitude (mV) } \\
\hline SITAGLIPTIN & $\mathrm{S}\left(10^{-8} \mathrm{M}\right)$ & $1.285 \pm 0.387$ & \multirow{2}{*}{$\mathrm{p}>0.05$} \\
\hline VILDA GLIPTIN & $\mathrm{V}\left(10^{-8} \mathrm{M}\right)$ & $226.4 \pm 161.2$ & \\
\hline SITAGLIPTIN & $\mathrm{S}\left(10^{-7} \mathrm{M}\right)$ & $1.294 \pm 0.387$ & \multirow{2}{*}{$\mathrm{p}<0.05^{* * *}$} \\
\hline VILDA GLIPTIN & $\mathrm{V}\left(10^{-7} \mathrm{M}\right)$ & $588.1 \pm 108.4$ & \\
\hline \multicolumn{4}{|c|}{ "ST" Height $(\mathrm{mV})$} \\
\hline SITAGLIPTIN & $\mathrm{S}\left(10^{-8} \mathrm{M}\right)$ & $0.3105 \pm 0.118$ & \multirow{2}{*}{$\mathrm{p}<0.05^{*}$} \\
\hline VILDA GLIPTIN & $\mathrm{V}\left(10^{-8} \mathrm{M}\right)$ & $434.8 \pm 177.1$ & \\
\hline SITAGLIPTIN & $\mathrm{S}\left(10^{-7} \mathrm{M}\right)$ & $0.3118 \pm 0.118$ & \multirow{2}{*}{$\mathrm{p}>0.05$} \\
\hline VILDA GLIPTIN & $\mathrm{V}\left(10^{-7} \mathrm{M}\right)$ & $75.70 \pm 162.8$ & \\
\hline \multicolumn{4}{|c|}{ “QT" Interval (ms) } \\
\hline SITAGLIPTIN & $\mathrm{S}\left(10^{-8} \mathrm{M}\right)$ & $19.34 \pm 19.21$ & \multirow{2}{*}{$\mathrm{p}>0.05$} \\
\hline VILDA GLIPTIN & $\mathrm{V}\left(10^{-8} \mathrm{M}\right)$ & $21.10 \pm 0.690$ & \\
\hline
\end{tabular}

$\mathrm{p}^{*}$ value $<0.05$ was considered statistically significant

\section{DISCUSSION}

Cell surface antigen CD26 is synonym of level. It was hypothesized that treatment with DPPDipeptidyl peptidase-4 (DPP-4). Its role in 4 inhibitors is cardio protective ${ }^{11}$. There are certain metabolic disorders, neoplasia and inflammatory endogenous substances like stromal derived factorconditions is well known. It is due to its proteolytic 1 (SDF-1), a known chemokine substrate of DPP-4 activity. DPP-4 is also present in kidney, small and other gastrointestinal hormones and cytokines intestine, liver and heart tissues ${ }^{8,9}$. DPP-4 break which have shown cardio protective effects in down products become soluble in body fluids ${ }^{10}$. experimental studies ${ }^{12}$. Sitagliptin reduces plasma Endogenous levels of glucagon-like peptide-1 glucose rise, body weight, myocardial fibrosis and (GLP-1) levels are raised by DPP-4 Inhibitors. oxidative stress ${ }^{13}$. In our experiment increased GLP-1 is responsible for lowering blood glucose chronotropicity and decreased coronary flow may 
be due to release of these cytokines. Opposite effect of Sitagliptin and Vildagliptin on inotropicity may be due to changes in the intracellular calcium on account of their different chemical structure and their influence. Sitagliptin antagonized the antihypertensive effect of enalapril in one of the experiments. This was considered to be due to activation of the sympathetic nervous system by substance $\mathrm{P}$ and neuropeptide $\mathrm{Y}$ which is responsible for vasodilatory effects ${ }^{14}$. Dipeptidyl peptidase (DPP-4) inhibitors can exert adverse cardiovascular effects.DPP-4 inhibitors may stimulate c AMP in cardiomyocytes ${ }^{15}$. Several experimental studies, clinical trials and met analysis have shown no conclusive results about risks and benefits of DPP-4 Inhibitors ${ }^{16,17}$.

\section{CONCLUSION}

DPP-4 Inhibitors may cause cardiovascular effects due to their non-incretin properties when prescribed. Moreover, their interaction with other antihypertensive like ACE inhibitors must be kept in view when prescribing sitagliptinwhich in our study has shown positive inotropic effects.

\section{Acknowledgements}

I am thankful to Shalamar Medical and Dental College for providing all sorts of facilities for completion of this project. I am also indebted to Wilshire pharmaceutical for providing raw material of drugs tested. I am grateful to the Lab staff of Department of Pharmacology for constant assistance in practical work.

\section{REFERENCES}

1. Haffner SM, Lehto S, Rönnemaa T, Pyörälä K, Laakso M. Mortality from coronary heart disease in subjects with type 2 diabetes and in nondiabetic subjects with and without prior myocardial infarction. New England Journal of medicine. 1998 Jul 23; 339(4):229-34.

2. Malmberg K, Yusuf S, Gerstein HC, Brown J, Zhao F, Hunt D, Piegas L, Calvin J, Keltai M, Budaj A. Impact of diabetes on long-term prognosis in patients with unstable angina and non-Q-wave myocardial infarction: results of the OASIS (Organization to Assess Strategies for Ischemic
Syndromes) Registry. Circulation. 2000 Aug 29; 102(9):1014-9.

3. McGuire DK, Emanuelsson $\mathrm{H}$, Granger CB, Magnus Ohman E, Moliterno DJ, White HD, Ardissino D, Box JW, Califf RM, Topol EJ. Influence of diabetes mellitus on clinical outcomes across the spectrum of acute coronary syndromes. Findings from the GUSTO-IIb Study. European Heart Journal. 2000 Nov 1; 21(21):1750-8.

4. Lim S, Choi SH, Shin H, Cho BJ, Park HS, Ahn BY, Kang SM, Yoon JW, Jang HC, Kim YB, Park KS. Effect of a dipeptidyl peptidase-IV inhibitor, des-fluoro-sitagliptin, on neointimal formation after balloon injury in rats. PloS one. 2012 Apr 6; 7(4):e35007.

5. Hausenloy DJ, Maddock HL, Baxter GF, Yellon DM. Inhibiting mitochondrial permeability transition pore opening: a new paradigm for myocardial preconditioning? Cardiovascular research. 2002 Aug 15;55(3):534-43.

6. Ye Y, Keyes KT, Zhang C, Perez-Polo JR, Lin YU, Birnbaum Y. The myocardial infarct size-limiting effect of sitagliptin is PKA-dependent, whereas the protective effect of pioglitazone is partially dependent on PKA. American Journal of Physiology-Heart and Circulatory Physiology. 2010 Mar 5; 298(5):H1454-65.

7. Xiao YF, Nikolskaya A, Jaye DA, Sigg DC. Glucagon-like peptide-1 enhances cardiac L-type $\mathrm{Ca} 2+$ currents via activation of the cAMPdependent protein kinase A pathway. Cardiovascular diabetology. 2011 Dec;10(1):6.

8. Calvert JW, Gundewar S, Jha S, Greer JJ, Bestermann WH, Tian R, Lefer DJ. Acute metformin therapy confers cardioprotection against myocardial infarction via AMPK-eNOS mediated signaling. Diabetes. 2007 Dec 12. 57:696-705.

9. Huisamen B, Genis A, Marais E, Lochner A. Pretreatment with a DPP-4 inhibitor is infarct sparing in hearts from obese, pre-diabetic rats. Cardiovascular drugs and therapy. 2011 Feb 1;25(1):13-20.

10. Meinert CL, Knatterud GL, Prout TE, Klimt CR. A study of the effects of hypoglycemic agents on vascular complications in patients with adult-onset diabetes. II. Mortality results. Diabetes. 1970; 19: Suppl-789.

11. Hardie DG. Minireview: the AMP-activated protein kinase cascade: the key sensor of cellular energy 
status. Endocrinology. 2003 Dec 1; 144(12):517983.

12. Hardie DG. The AMP-activated protein kinase pathway-new players upstream and downstream. Journal of cell science. 2004 Nov 1; 117(23):547987.

13. Huisamen B, Genis A, Marais E, Lochner A. Pretreatment with a DPP-4 inhibitor is infarct sparing in hearts from obese, pre-diabetic rats. Cardiovascular drugs and therapy. 2011 Feb 1; 25(1):13-20.

14. Marney A, Kunchakarra S, Byrne L, Brown NJ. Interactive hemodynamic effects of dipeptidyl peptidase-IV inhibition and angiotensin-converting enzyme inhibition in humans. Hypertension. 2010 Oct $1 ; 56(4): 728-33$.

15. Deacon CF. A review of dipeptidyl peptidase-4 inhibitors. Hot topics from randomized controlled trials. Diabetes, Obesity and Metabolism. 2018 Feb; 20:34-46.

16. Ogawa S, Ishiki M, Nako K, Okamura M, Senda M, Mori T, Ito S. Sitagliptin, a dipeptidyl peptidase-4 inhibitor, decreases systolic blood pressure in Japanese hypertensive patients with type 2 diabetes. The Tohoku journal of experimental medicine. 2011; 223(2):133-5.

17. Lamanna C, Monami M, Bartoli N, Zannoni S, Mannucci E. Dipeptidyl peptidase-4 inhibitors and cardiovascular events: a protective effect?. In Diabetologia 2011 Sep 1 (Vol. 54, pp. S109-S109). 233 SPRING ST, NEW YORK, NY 10013 USA: SPRINGER.
18. Deacon CF. A review of dipeptidyl peptidase-4 inhibitors. Hot topics from randomized controlled trials. Diabetes, Obesity and Metabolism. 2018 Feb; 20:34-46.

19. Ogawa S, Ishiki M, Nako K, Okamura M, Senda M, Mori T, Ito S. Sitagliptin, a dipeptidyl peptidase-4 inhibitor, decreases systolic blood pressure in Japanese hypertensive patients with type 2 diabetes. The Tohoku journal of experimental medicine. 2011; 223(2):133-5.

20. Lamanna C, Monami M, Bartoli N, Zannoni S, Mannucci E. Dipeptidyl peptidase-4 inhibitors and cardiovascular events: a protective effect?. In Diabetologia 2011 Sep 1 (Vol. 54, pp. S109-S109). 233 SPRING ST, NEW YORK, NY 10013 USA: SPRINGER

\section{Corresponding Author:}

A Shabbir Ali Bhatti

Department of Pharmacology,

Shalamar Medical and Dental College, Lahore.

Email: shabbiralibhatti@gmail.com 